\title{
In Reply: Comment on "Effect of Extracorporeal Shockwave Therapy Versus Intra-articular Injections of Hyaluronic Acid for the Treatment of Knee Osteoarthritis"
}

\author{
June-Kyung Lee, MD, Bong-Yeon Lee, MD, Woo-Yong Shin, MD, \\ Min-Ji An, MD, Kwang-Ik Jung, MD, Seo-Ra Yoon, MD
}

Department of Rehabilitation Medicine, Gwangju Veterans Hospital, Gwangju, Korea

I appreciate your interest of our study and are grateful for the comment. We evaluated and compared the effects and outcomes of the extracorporeal shock wave therapy and intra-articular injections of hyaluronic acid in patients with knee osteoarthritis using the visual analogue scale, Western Ontario and McMaster Universities Osteoarthritis Index (WOMAC), Lequesne index, 40-meter fast-paced walk test, and stair-climb test. The Osteoarthritis Research Society International recommended performance-based tests to assess the physical function in patients with knee osteoarthritis [1]. Therefore, we conducted a 40-m fast-paced walk test and a stair-climb test to further evaluate the patient's physical function. As is correct in your opinion assessment, the gait analysis evaluation is an objective instrumentation to support the effect of the extracorporeal shock wave therapy and the intra-articular injections of hyaluronic acid in patients with knee osteoarthritis. The pathology of the patient's osteoarthritis is commonly degenerative and chronic. We agree that a long-term follow-up study is useful to achieve the management of knee osteoarthritis. We are going to apply it to the following study and will review the results of this follow-up effort.

\section{REFERENCE}

1. Dobson F, Hinman RS, Roos EM, Abbott JH, Stratford P, Davis AM, et al. OARSI recommended performancebased tests to assess physical function in people diagnosed with hip or knee osteoarthritis. Osteoarthritis Cartilage 2013;21:1042-52.

\footnotetext{
Corresponding author: Seo-Ra Yoon

Department of Rehabilitation Medicine, Gwangju Veterans Hospital, 99 Cheomdanwolbong-ro, Gwangsan-gu, Gwangju 62284, Korea. Tel: +82-62-6026295, Fax: +82-62-602-6230, E-mail: standupmd@hanmail.net

ORCID: June-Kyung Lee (http://orcid.org/0000-0002-9900-0961); Bong-Yeon Lee (http://orcid.org/0000-0002-2975-6333); Woo-Yong Shin (http:// orcid.org/0000-0002-6080-2617); Min-Ji An (http://orcid.org/0000-0001-6018-2529); Kwang-Ik Jung (http://orcid.org/0000-0002-9754-5925); Seo-Ra Yoon (http://orcid.org/0000-0002-3694-0710).
}

(c) This is an open-access article distributed under the terms of the Creative Commons Attribution Non-Commercial License (http://creativecommons.org/ licenses/by-nc/4.0) which permits unrestricted noncommercial use, distribution, and reproduction in any medium, provided the original work is properly cited. Copyright () 2018 by Korean Academy of Rehabilitation Medicine 